\title{
AUTOMATED SHOPPING TROLLEY FOR BILLING SYSTEM
}

\author{
Abhishek, Bhumika K M, Chandan GN, C V Yashaswini \\ Department Of CS\&E \\ BIET, Davangere, Karnataka, India \\ Prof. Raghu B R \\ Asst.Professor Department Of CS\&E \\ BIET, Davangere, Karnataka, India
}

\begin{abstract}
-with the development of wireless technology there are various fields where in we can use this technology and use of wireless technology is favorable now a day. As we know that during special offers and weekends we observe rush at supermarkets and due to this the billing process which often takes more time rather than picking the products into the trolley and customer cannot stand for too long in a queue for billing purpose so, here we can makes use of the automated shopping trolley for billing system, the customer will self-scan the product by himself and prepare the bill. Hence, there will be no long queue in the supermarket at billing counter for billing purpose.
\end{abstract}

Keywords- Raspberry pi device, Barcode Scanner, LCD, display, Load cell

\section{INTRODUCTION}

Nowadays people prefer going for the supermart so that they could get all kind of products at the single roof rather than going for the different shops for the limited products. With the increasing needs of humankind there is the need for development of new technology to make day to day work easy and effortless. Shopping is one of the thing in which we spend considerable amount of time and to know charge of money for goods is a time consuming process due to standing in a long queue for billing process. In this paper we have proposed the shopping trolley. This trolley is not similar to the trolley we use nowadays. It is the newer and innovative version of the basic trolley. This smart trolley consists of raspberry pi, barcode scanner, LCD display with Wi-Fi connection load cell, keypad, HX711.

With the help of barcode scanner which is present at the trolley connected with the raspberry pie so customer can self-scan the product and aware of total cost of the bill as the overall information i.e. product name, product price, product weight is displayed on the screen which is integrated on the trolley itself. The purpose of the raspberry pi is to operate the overall system. It works as a mini computer.

Now, further after completing the shopping customer will go to the billing counter only for payment and as the overall total bill is already displayed on the LCD screen which is connected to raspberry pie and customer is already aware about total bill. This system is also beneficial for the customer who has certain budget limit. This automated shopping trolley for billing system will provide customer satisfaction as the customer will not stand in a long queue to know the total charge for goods he/she purchased.

\section{LITRATURE SURVEY}

PAPER[1]: Yen-Lin Chen, Jin-Shyan Lee, "Development of Smart Shopping Carts with Customer Oriented Service"

From this paper we referred about how customer access the RFID card ,so this could help to reduce the waiting time at the billing counter and makes customer efficient with the system interface.

PAPER[2]: $\mathbf{P}$ Chandrasekhar, $\mathbf{T}$ Sangeetha, "Smart Shopping Cart with Automatic Billing System through RFID and ZigBee"

From this paper we referred about how the data is send to the central billing system so that the final billing is generated at both ends i.e. at the trolley as well as at the central billing counter.

PAPER[3]: Ruinian Li, Tianyi, Nicholas Capurso, Jiguo Yu, "IoT Applications on Secure Smart Shopping System"

From this paper we referred about how the system can ensure secure communication protocol and how to achieve the theft control mechanism

PAPER[4]: Akshay Kumar, Abhinav Gupta, S. Balamurugan, S Balaji, R Marimuthu, "Smart Shopping Cart"

From this paper we referred about how to delete the product that have already been added to the trolley car and to reduce the human error.

PAPER[5]: Zeeshan Ali, Reena Sonkusare, "RFID based Smart Shopping: An overview"

From this paper we referred about which micro-controller is efficient to support the camera feature without using the external driver so that it provide the customer a better service. 


\section{International Journal of Engineering Applied Sciences and Technology, 2021 \\ Vol. 6, Issue 2, ISSN No. 2455-2143, Pages 26-30 \\ Published Online June 2021 in IJEAST (http://www.ijeast.com)}

\section{PROBLEM STATEMENT}

The problem faced by the customer is that they need to wait at the billing counter until the employee of the mart scan each every product purchased by the customer to generate the filling billing this results other customer to follow the tedious queue

One common problem faced by the customer is BUDGETLIMIT. usually before we start to shop we have a fixed budget limit but while shopping we do not make record of the product price such that we keep on adding the products to our cart later when we go for the billing counter we realize that our budget have been exceeded. And while shopping it is difficult for the customers to search for product in such a huge mall.

\section{PROPOSED SOLUTION}

This project proposes a system implementation of wireless technology using Raspberry Pi. Here the purchased product name along with the corresponding product price and weight is displayed on the LCD display.

trolley which has a LCD display, load cell for weighing and theft detection, Wi-Fi module which communicates between trolley and main computer for the purpose of billing, then the switch module to add or remove products, scan the product and finalize the bill.

When a product is put into the cart, the measure of the load cell becomes an integral factor. The weight of the product is calculated and then transmitted to the main server via Wi-Fi. If the weight of the product calculated by the load-cell is not identical to the actual weight of the product stored in the main database, then it is considered as a conflict and an alert message is sent to the main server and the buzzer mounted on the cart will start beeping.

If the customer wants to remove a product from the trolley, they must first scan the corresponding product RFID, which will be notified through a message on the LCD as "PRODUCT DELETED".

\section{OBJECTIVES}

To develop an automated shopping trolley, we have fixed load cell, barcode scanner in the trolley itself.

To design this system, we need to connect the barcode scanner and load cell to the raspberry pi.

To achieve our desired output, we need to scan the product ID that has to match its information with the information present in the database.

To determine the theft control, we have used load cell as the main objective in our project.

\section{ARCHITECHTURE OF PROPOSED SYSTEM}

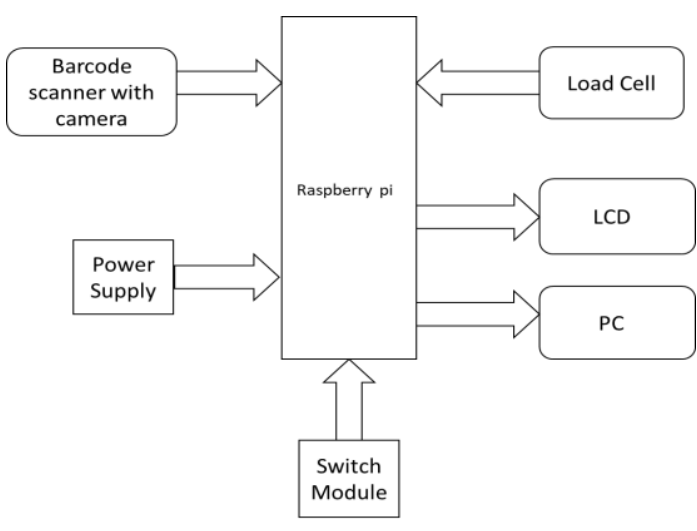

VII. WORKFLOW DIAGRAM

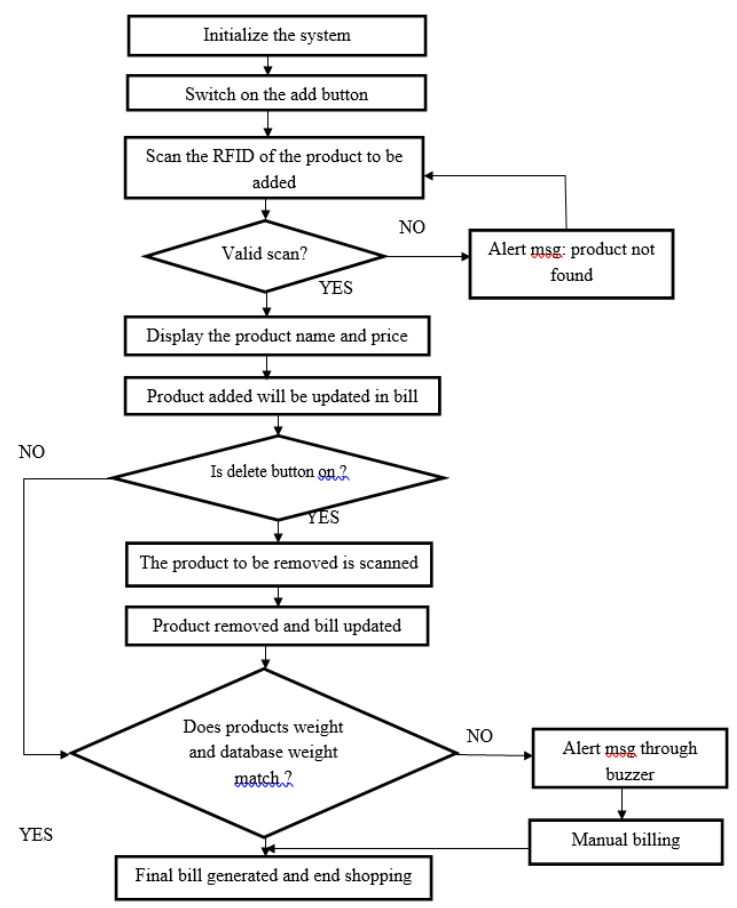

The stages followed for designing this arrangement:

1. Initialized the system i.e. power up microcontroller, LCD, keypad, RFID scanner etc.

2. To add the product to the trolley, switch on the add button.

3. Scan the RFID of the particular product with RFID scanner and put them in a cart.

4. Check if the RFID\& its weight match with the value stored in the Database.

5. If yes then, add particular product to the cart, the product name and price will be displayed on LCD and amount of bill will be updated if no, then buzzer is played and an alert notification is sent to the control server.

6. Check if delete button is ON.

7. If yes then anyone wants to remove the particular product then scan RFID for removing the product, the particular 
product will be removed and the bill will be updated. If no then check if the RFID\& its weight match with the value stored in the Database.

8. Check if the products weight and database match.

9. If yes then Scan RFID for end shopping and final amount of bill will be generated at the payment counter. If no then alert notification through buzzer, then it finally moves to manual billing to end shopping.

\section{CONCULUSION AND FUTURE SURVEY}

This research paper will help the people to reduce manpower required in billing section. This can reduce the expenses incurred by the management. Users can be aware of the total bill amount during the time of purchase. In future this system will also increase customer satisfaction which will be beneficial for supermarket owner as well as the customer.

\section{REFERENCES}

[1]Yen-Lin Chen, Jin-Shyan Lee, "Development of Smart Shopping Carts with Customer Oriented Service", ISSN: $2325-$ 0925, System science and engineering (ICSSE), 7 July 2016.

[2] P Chandrasekhar, T Sangeetha, "Smart Shopping Cart with Automatic Billing System through RFID and ZigBee", ISBN: 978-1-4799-3698-4, Information Communication and Embedded Systems (ICICES), 27 Feb 2014.
[3] Ruinian Li, Tianyi, Nicholas Capurso, Jiguo Yu, "IoT Applications on Secure Smart Shopping System”, ISSN: 23274662, IEEE Internet of Things Journal, Volume: 4, Issue: 6, Dec 2017.

[4] Akshay Kumar, Abhinav Gupta, S. Balamurugan, S Balaji, R Marimuthu, "Smart Shopping Cart" ISBN:978-1-5386-17175, Microelectronic Devices, Circuits and Systems(ICMDCS), Aug 2017.

[5] Zeeshan Ali, ReenaSonkusare, "RFID based Smart Shopping: An overview”, ISBN: 978-1-4799-7318-7, Advances in Communication and Computing Technologies (ICACACT), Aug 2014. 